Quim. Nova, Vol. 34, No. 8, 1370-1377, 2011

\title{
AVALIAÇÃO DE PROCESSO OXIDATIVO AVANÇADO PELO REAGENTE DE FENTON EM CONDIÇÕES OTIMIZADAS NO TRATAMENTO DE LIXIVIADO DE ATERRO SANITÁRIO COM ÊNFASE EM PARÂMETROS COLETIVOS E CARACTERIZAÇÃO DO LODO GERADO
}

\author{
Wagner Guadagnin Moravia*, Liséte Celina Lange e Míriam Cristina Santos Amaral \\ Departamento de Engenharia Sanitária e Ambiental, Escola de Engenharia, Universidade Federal de Minas Gerais, Av. Antônio \\ Carlos, 6627, 31270-901 Belo Horizonte - MG, Brasil
}

Recebido em 30/11/10; aceito em 8/4/11; publicado na web em 10/6/11

\begin{abstract}
EVALUATE OF ADVANCED OXIDATIVE PROCESS BY FENTON REAGENT UNDER OPTIMIZED CONDITIONS FOR LANDFILL LEACHATE TREATMENT OF WITH EMPHASIS ON COLLECTIVE PARAMETERS AND CHARACTERIZATION OF SLUDGE GENERATED. An alternative for landfill leachate treatment are advanced oxidation processes by Fenton's reagent (AOP/Fenton). In this context, the aim of this paper was to evaluate, in a bench scale, the treatability of leachate pós-AOP/Fenton characterizing the supernatant and the sludge generated separately. Observed in optimal conditions, high removal efficiency of COD (76.7\%), real color (76.4\%) and humic substances (50\%). Organic compounds were detected in the sludge (2.465 mg COD L $\left.{ }^{-1}\right)$ and high concentration of iron $\left(1.757 \mathrm{mg} \mathrm{L}^{-1}\right)$ as was expected. Finally, the sludge generated showed low settling hindering their separation by sedimentation $\left(\mathrm{SVI}=321 \mathrm{~mL} \mathrm{~g}^{-1}\right)$.
\end{abstract}

Keywords: advanced oxidative process; landfill leachate; characterization.

\section{INTRODUÇÃO}

O lixiviado de aterro sanitário pode ser definido como o líquido proveniente da umidade natural e água de constituição presentes na matéria orgânica dos resíduos, dos produtos da degradação biológica dos materiais orgânicos presentes e da água de infiltração na camada de cobertura e interior das células de aterramento, somado a materiais dissolvidos ou suspensos extraídos da massa de resíduos. Este efluente é caracterizado pela intensa cor e elevada concentração de matéria orgânica refratária, amônia e compostos tóxicos. Quando descartado sem tratamento prévio, este efluente causa problemas ambientais, como a toxicidade para a biota existente no solo e comunidades aquáticas atingidas, a diminuição do oxigênio dissolvido e a eutrofização nos corpos d'águas receptores.

As técnicas mais usuais para o tratamento de lixiviados são as fundamentadas em processos biológicos, sendo que estas têm se mostrado insuficientes para o atendimento aos padrões de lançamento estabelecidos pela legislação nacional (Resolução CONAMA n ${ }^{\circ} 357$, de 17/3/2005), principalmente no caso de lixiviados de aterro sanitário estabilizado em relação aos parâmetros referentes à matéria orgânica, cor, nutrientes, cloretos e alcalinidade. Estudos de tratabilidade de lixiviado reportados na literatura, em escala demonstrativa, com o lixiviado do aterro sanitário de Belo Horizonte, mostraram que o emprego de filtros anaeróbios conjugados com lagoa facultativa não obteve êxito. Este fato se deve, provavelmente, à alta concentração de amônia, no caso do filtro, e baixa concentração de oxigênio dissolvido somada ao elevado valor de cor real, característicos do efluente em questão para a lagoa facultativa. A lagoa aerada apresentou eficiência média de remoção de DQO solúvel aproximadamente de $20 \%$ e baixa remoção de nutrientes quando operada com tempo de detenção hidráulica de 7 dias, mostrando que essas tecnologias são insuficientes para tratabilidade de lixiviados com recalcitrância. ${ }^{1}$
Uma alternativa para este tipo de lixiviado são os tratamentos baseados em processos químicos capazes de promover a degradação ou, até mesmo, a mineralização da matéria poluente refratária, podendo haver a combinação entre diferentes técnicas ou serem conjugados com processos biológicos. ${ }^{2}$

Os processos oxidativos avançados (POA) envolvem a geração de radicais hidroxilas $\left({ }^{\circ} \mathrm{OH}\right)$, altamente reativos, que têm a capacidade de destruição total de muitos poluentes orgânicos. Os radicais livres formados atacam o composto orgânico levando à sua oxidação completa, produzindo $\mathrm{CO}_{2}$ e $\mathrm{H}_{2} \mathrm{O}$, ou quando resulta em uma oxidação parcial, geralmente ocorre um aumento da biodegradabilidade dos poluentes e, neste caso, os compostos orgânicos residuais podem ser removidos por meio de técnicas biológicas.

O POA pelo reagente de Fenton (POA/Fenton) vem sendo extensivamente estudado nos últimos anos e tem sido considerado a técnica de melhor custo benefício entre os processos oxidativos avançados. ${ }^{3}$ No POA/Fenton o peróxido de hidrogênio é empregado para a geração de radicais hidroxilas, espécie chave para a oxidação de compostos orgânicos. Entretanto, é necessária a adição de ativadores como sais ferrosos. ${ }^{4}$ Os compostos orgânicos também são removidos por coagulação, que acontece durante a etapa de formação do lodo. O POA/Fenton ocorre em um reator simples, sem a necessidade de equipamentos complexos e condições extremas de temperatura e pressão. Outra vantagem é sua maior facilidade operacional em relação a outras técnicas de POA, como os processos fundamentados em ozônio e radiação ultravioleta, que necessitam de gerador de $\mathrm{O}_{3}$ e fonte de $\mathrm{UV}$, respectivamente. As reações 1 a 4 mostram de forma simplificada o mecanismo de reação da decomposição catalítica do $\mathrm{H}_{2} \mathrm{O}_{2}$ por sais de ferro, em meio ácido. 5

$\mathrm{Fe}^{2+}+\mathrm{H}_{2} \mathrm{O}_{2} \rightarrow \mathrm{Fe}^{3+}+\mathrm{OH}^{-}+\mathrm{HO}^{\bullet}$ (início da cadeia de reação) (1) 


$$
\begin{gathered}
\mathrm{R}^{\cdot}+\mathrm{Fe}^{3+} \rightarrow \mathrm{R}^{+}+\mathrm{Fe}^{2+} \\
\mathrm{Fe}^{2+}+\mathrm{HO}^{\cdot} \rightarrow \mathrm{Fe}^{3+}+\mathrm{OH}^{-} \text {(final da reação - baixo substrato) }
\end{gathered}
$$

onde $\mathrm{Fe}^{2+}$ e $\mathrm{Fe}^{3+}$ representam as espécies hidratadas, $\mathrm{Fe}\left(\mathrm{H}_{2} \mathrm{O}\right)_{6}{ }^{2+} \mathrm{e}$ $\mathrm{Fe}\left(\mathrm{H}_{2} \mathrm{O}\right)_{6}{ }^{3+}$, respectivamente. A reação 1 é conhecida como a reação de Fenton, embora muitas outras reações ocorram no sistema. Outras reações secundárias que ocorrem em misturas de ferro e peróxido de hidrogênio em meio aquoso são representadas nas reações 5 a 8 .

$$
\begin{gathered}
\mathrm{Fe}^{3+}+\mathrm{H}_{2} \mathrm{O}_{2} \rightarrow \mathrm{Fe}^{2+}+\mathrm{H}^{+}+\mathrm{HO}_{2}^{\cdot} \\
\mathrm{Fe}^{3+}+\mathrm{HO}_{2}^{\cdot} \rightarrow \mathrm{Fe}^{2+}+\mathrm{H}^{+}+\mathrm{O}_{2} \\
\mathrm{Fe}^{2+}+\mathrm{HO}_{2}^{\cdot} \rightarrow \mathrm{Fe}^{3+}+\mathrm{HO}_{2}^{-} \\
\mathrm{H}_{2} \mathrm{O}_{2}+\mathrm{HO}^{\cdot} \rightarrow \mathrm{H}_{2} \mathrm{O}+\mathrm{HO}_{2}
\end{gathered}
$$

A reação 5 constitui o início de um processo conhecido como reação tipo Fenton (Fenton-like) e contribui indiretamente para o aporte de radicais hidroperoxila no sistema. As reações 6 e 7 indicam a regeneração do $\mathrm{Fe}^{2+}$ no ciclo catalítico, o que dá sustentabilidade ao processo. Enquanto houver peróxido de hidrogênio disponível no sistema, as espécies de ferro serão continuamente cicladas entre $\mathrm{Fe}^{2+}$ e $\mathrm{Fe}^{3+}$, a menos que reações adicionais resultem na formação de óxidos e hidróxidos insolúveis de ferro. A reação 8 representa o sequestro de radicais hidroxila por parte do peróxido de hidrogênio, geralmente quando este se apresenta em concentrações excessivas, o que causa efeito inibitório na degradação dos poluentes.

Uma consideração importante é que para o sucesso do tratamento baseado no POA/Fenton é fundamental a otimização do processo através de seus fatores condicionantes. Isso se faz necessário em função das diferentes características de cada efluente a ser tratado. Uma das formas de otimizar os fatores condicionantes POA/Fenton em função de uma determinada resposta é a técnica de delineamentos experimentais, que consiste em projetar um bloco de experimentos de forma que seja capaz de fornecer exatamente um determinado tipo de informação específica. Na aplicação desta técnica deve-se desenvolver um estudo de otimização para os diferentes fatores (variáveis) que interferem no processo, com o objetivo de se obter o melhor resultado analítico possível. ${ }^{6}$

Um dos fatores limitantes da aplicação do POA/Fenton é a geração de lodo no processo. Este lodo possui elevada concentração de ferro (complexo hidróxido férrico) o que torna necessária a sua separação do efluente tratado. ${ }^{7}$ Convencionalmente, é necessária uma etapa de neutralização/precipitação para a separação do lodo gerado, onde se exigem, normalmente, tempos elevados em função da baixa sedimentabilidade deste subproduto, incrementando significativamente o tempo do tratamento.

Neste contexto, o objetivo desta pesquisa foi avaliar, em escala de bancada, a tratabilidade de lixiviado pós-POA/Fenton caracterizando, separadamente, o sobrenadante e o lodo gerado.

\section{PARTE EXPERIMENTAL}

\section{Amostragem}

O lixiviado utilizado para a realização dos experimentos proveio do Aterro Sanitário da Central de Tratamento de Resíduos Sólidos (CTRS) da cidade de Belo Horizonte/MG, Brasil. O aterro ocupa uma área de 133 ha, possui células de aterramento com diferentes idades e características e encontra-se com suas atividades encerradas. O lixiviado bruto foi coletado no tanque de equalização da Estação
Amarela de Tratamento de Efluentes da CTRS, que recebe lixiviado da célula AC05 com idade respectiva de 9 anos.

\section{Caracterização coletiva}

\section{Parâmetros convencionais}

A caracterização das amostras contemplou os seguintes parâmetros físico-químicos: cor real e aparente, demanda química de oxigênio (DQO) (método $5220 \mathrm{C}$ ), demanda bioquímica de oxigênio (DBO) (método 5210B), carbono orgânico total (COT) (método 5310B), pH, alcalinidade (método 2320B), série sólidos (métodos 2540B e 2540D), nitrogênio total (método 4500-N C) e amoniacal (método 4500- $\mathrm{NH}_{3} \mathrm{~B}$ e C), fósforo (método 4500-P C), cloretos (método 4500-Cl C) e metais, realizados em conformidade com as recomendações do Standard Methods for the Examination of Water and Wastewater. ${ }^{8}$

O lodo gerado no POA/Fenton foi separado por decantação (com o auxílio da neutralização), homogeneizado e caracterizado quanto aos seguintes parâmetros físico-químicos: DQO, carbono total (CT), série sólidos e ferro.

\section{DQO inerte}

Os ensaios de DQO inerte foram realizados de acordo com o método proposto por Germili et al. ${ }^{9}$ e consistiram na montagem de pares de reatores aeróbios, com capacidade para $2 \mathrm{~L}$, em regime de batelada, um alimentado com a amostra de concentração conhecida e o outro com solução de glicose de concentração equivalente. Os reatores foram inoculados com lodo de reatores de lodos ativados da ETE Arrudas/COPASA-MG com concentração de SSV de 100 mg $\mathrm{L}^{-1}$, alimentados com $2 \mathrm{~mL}$ de solução de cada um dos nutrientes empregados no ensaio de DBO e aerados através de compressores elétricos. Os reatores foram monitorados utilizando-se o parâmetro DQO até que a atividade biológica fosse encerrada.

\section{Biodegradabilidade}

A avaliação da biodegradabilidade foi realizada através da adaptação do método de Zahn-Wellens, ${ }^{10}$ onde foram empregados reatores de $2 \mathrm{~L}$, alimentados com lixiviado unicamente no início do teste, $2 \mathrm{~mL}$ de solução de cada nutriente empregado no ensaio de DBO e inóculo na concentração de $100 \mathrm{mg} \mathrm{L}^{-1}$ de SSV. Os reatores foram submetidos à aeração por meio de compressores elétricos e a depleção do substrato foi monitorada por meio de análise de DQO solúvel (filtrada) durante 30 dias, com periodicidade de aproximadamente 2 dias. A biodegradabilidade foi determinada pelo percentual da DQO removida.

\section{Distribuição de massa molar}

A distribuição de massa molar das amostras foi determinada utilizando-se uma célula de ultrafiltração (série 8000, modelo 8200, marca Amicon), operada em paralelo. A ultrafiltração foi realizada utilizando membranas com massa molar de corte de 1, 10 e $100 \mathrm{kDa}$. Inicialmente as membranas foram lavadas com água deionizada, e depois de se filtrar aproximadamente $150 \mathrm{~mL}$ de água deionizada, a célula foi despressurizada e carregada com a amostra previamente filtrada em um filtro de vidro AP40. Após a filtração de aproximadamente $180 \mathrm{~mL}$ de amostra, outros $100 \mathrm{~mL}$ de água deionizada foram acrescentados e a ultrafiltração continuou até que o volume retido fosse menor que $20 \mathrm{~mL}$. A célula despressurizada era então deixada sob agitação por cerca de 10 min para recuperar compostos eventualmente adsorvidos à membrana, e o volume aferido com água destilada para $20 \mathrm{~mL}$. As frações retidas foram analisadas quanto à concentração de carboidratos, lipídeos, proteínas, substâncias húmicas e DQO de acordo com os cálculos relacionados na Tabela 1.

Os resultados foram expressos em termos de concentração $\left(\mathrm{mg} \mathrm{L}^{-1}\right)$. 
Tabela 1. Cálculos para determinação das concentrações de lipídeos, carboidratos, proteínas, substâncias húmicas e DQO na caracterização por distribuição de massa molar

\begin{tabular}{lc}
\hline Classificação & Cálculo \\
\hline $\mathrm{MM}>100 \mathrm{kDa}$ & $C_{\text {retido } \rightarrow 100 k D a} \times v / V$ \\
$10<\mathrm{MM}<100 \mathrm{kDa}$ & $\left(C_{\text {retido } \rightarrow 10 k D a}-C_{\text {retido } \rightarrow 100 \mathrm{kDa}}\right) \times v / V$ \\
$1<\mathrm{MM}<10 \mathrm{kDa}$ & $\left(C_{\text {retido } \rightarrow 1 k D a}-C_{\text {retido } \rightarrow 10 k D a}\right) \times v / V$ \\
$\mathrm{MM}<1 \mathrm{kDa}$ & $\left(C_{\text {bruto }} \times V\right)-\left(C_{\text {retido } \rightarrow 1 k D a} \times v\right) / V$ \\
\hline
\end{tabular}

$\mathrm{MM}=$ massa molar $(\mathrm{kDa}) ; C=$ concentração de carboidratos, lipídeos, proteínas, substâncias húmicas ou $\mathrm{DQO}\left(\mathrm{mg} \mathrm{L}^{-1}\right) ; v=$ volume do retido $(\mathrm{L}) ; V=$ volume da amostra bruta carregada na célula de ultrafiltração (L).

\section{Substâncias húmicas}

Para a determinação da concentração de substâncias húmicas das amostras foi empregado o método de Lowry modificado. ${ }^{11}$ Este método consiste na execução do método de quantificação de proteínas de Lowry et al. ${ }^{12}$ com e sem a adição de $\mathrm{CuSO}_{4}$, onde a interferência da cor no ensaio sem a adição de $\mathrm{CuSO}_{4}$ é atribuída principalmente às substâncias húmicas. Frolund et al. ${ }^{11}$ observaram uma redução de absorbância em torno de $20 \%$ para a curva padrão construída para a proteína soro albumina bovina (BSA) quando medida sem a adição de $\mathrm{CuSO}_{4}$; e não observaram redução de absorbância para a curva construída para as substâncias húmicas quando foi empregado ácido húmico comercial como padrão.

Visando a adequação do ensaio para o efluente em estudo, a concentração de substâncias húmicas em função da absorbância foi determinada através da construção das curvas padrão para a proteína BSA e substâncias húmicas, variando-se a concentração em 0,20 , 40, 70, 100 e $120 \mathrm{mg} \mathrm{L}^{-1}$ para proteínas e $0,17,51$ e $102 \mathrm{mg} \mathrm{L}^{-1}$ para substâncias húmicas, efetuando-se as leituras de absorbâncias com e sem a adição de $\mathrm{CuSO}_{4}$. Para o padrão de substâncias húmicas foi utilizado ácido húmico técnico, marca Sigma-Aldrich. As Equações 9 a 12 representam o cálculo do fator de redução de absorbância discretizado em função das absorbâncias dissociadas para proteínas e substâncias húmicas.

$$
\begin{gathered}
\mathrm{A}_{\mathrm{c} / \mathrm{Cu}}=\mathrm{A}_{\text {proténas }}+\mathrm{A}_{\text {substâncias húmicas }} \\
\mathrm{A}_{\mathrm{s} / \mathrm{Cu}}=\mathrm{F} \cdot \mathrm{A}_{\text {proteínas }}+\mathrm{A}_{\text {substâncias húmicas }}
\end{gathered}
$$

sendo que: $\mathrm{F}$ = Fator de redução de absorbância.

$$
\text { Para }[\text { substâncias húmicas }]=0 \rightarrow \mathrm{A}_{\text {substâncias húmicas }}=0
$$

Assim:

$$
\begin{aligned}
& \mathrm{A}_{\mathrm{c} / \mathrm{Cu}}=\mathrm{A}_{\text {protéínas }} \text { e } \mathrm{A}_{\mathrm{s} / \mathrm{Cu}}=\mathrm{F} \cdot \mathrm{A}_{\text {proteínas }} \rightarrow \\
& \rightarrow \mathrm{A}_{\mathrm{s} / \mathrm{Cu}}=\mathrm{F} \cdot \mathrm{A}_{\mathrm{c} / \mathrm{Cu}} \rightarrow \mathrm{F}=\mathrm{A}_{\mathrm{s} / \mathrm{Cu}} / \mathrm{A}_{\mathrm{c} / \mathrm{Cu}}
\end{aligned}
$$

em que: $\mathrm{A}_{\mathrm{c} / \mathrm{Cu}}=$ absorbância obtida nos ensaios com a adição $\mathrm{CuSO}_{4}$; $\mathrm{A}_{\mathrm{s} / \mathrm{Cu}}=$ absorbância obtida nos ensaios sem a adição $\mathrm{CuSO}_{4} ; \mathrm{A}_{\text {proteínas }}$ = estimativa de absorbância dissociada para proteínas; $\mathrm{A}_{\text {substâncias }}=$ estimativa de absorbância dissociada para substâncias húmicas.

É importante observar que este método pode apresentar variações em função do tipo de ácido húmico utilizado. Frolund et al. ${ }^{11}$ testaram dois tipos de ácido húmico comercial de diferentes fornecedores e constataram diferença de $12 \%$ no fator de redução de absorbância.

\section{Especiação das substâncias húmicas}

A especiação das substâncias húmicas das amostras foi realizada através da quantificação desses compostos em alíquotas separadas do efluente fracionadas em massas molares entre 5, 10 e $100 \mathrm{kDa}$, segundo as massas molares das espécies de substâncias húmicas propostas por McBride, conforme mostradas na Tabela 2. ${ }^{13}$

Tabela 2. Características de massa molar para espécies de substâncias húmicas

\begin{tabular}{lccc}
\hline & Ácidos fúlvicos & Ácidos húmicos & Humina \\
\hline Massa molar (Da) & $640-5.000$ & $10.000-100.000$ & $>100.000$ \\
\hline
\end{tabular}

\section{Operação do POA/Fenton}

A etapa de oxidação consistiu, para cada ensaio, no ajuste do $\mathrm{pH}$ de reação com ácido sulfúrico (adição lenta) de $1 \mathrm{~L}$ de lixiviado bruto empregado, seguido pela adição de solução de peróxido de hidrogênio $\left(1,7 \mathrm{~g} \mathrm{H}_{2} \mathrm{O}_{2} / \mathrm{g} \mathrm{DQO}_{\text {Lixiviado bruto }}\right)$ e sulfato ferroso hepta-hidratado sólido $\left(\mathrm{FeSO}_{4} \cdot 7 \mathrm{H}_{2} \mathrm{O}: \mathrm{H}_{2} \mathrm{O}_{2}=1: 5,3\right)$ conforme valores otimizados por Moravia. ${ }^{14}$ Durante a reação o sistema foi mantido sob agitação. Alíquotas da amostra pré e pós-tratamento foram coletadas e analisadas, sendo que os ensaios foram realizados em equipamento Jar Test. Os reagentes utilizados nos ensaios de POA/Fenton foram solução de peróxido de hidrogênio em concentração de $30 \%$ (v/v), marca Vetec, e reagente sólido sulfato ferroso hepta-hidratado, marca Synth.

\section{Avaliação da capacidade adsortiva do lodo gerado no POA/Fenton}

\section{Cinética de adsorção}

A adsorção da matéria orgânica no lodo gerado no POA foi avaliada. Inicialmente, a preparação do lodo puro foi através da aplicação dos procedimentos do processo oxidativo avançado pelo reagente de Fenton, nas mesmas condições operacionais, em água destilada. O lodo gerado foi decantado e submetido à análise de sólidos totais. Os ensaios foram em reservatórios de $2 \mathrm{~L}$, com diluições do lixiviado de 0, 20, 40, 60 e 80\%, respectivamente. Em cada reservatório foi adicionado lodo puro em quantidade equivalente à média de lodo gerado calculada na etapa de avaliação do processo. Os reservatórios foram mantidos sob agitação de $115 \mathrm{rpm}$. Durante $24 \mathrm{~h}$, periodicamente alíquotas do líquido eram coletadas, filtradas e analisadas quanto à concentração de DQO. A quantidade adsorvida em relação ao tempo foi calculada através da remoção de DQO. Os dados da cinética de adsorção foram analisados usando os modelos cinéticos de primeira ordem e segunda ordem.

\section{Isotermas de adsorção}

Para obtenção das isotermas de adsorção foram realizados ensaios semelhantes aos descritos no item anterior. Durante $24 \mathrm{~h}$, periodicamente, alíquotas do líquido eram coletadas, filtradas e analisadas quanto à concentração de DQO. A quantidade de matéria orgânica adsorvida no equilíbrio, $\mathrm{q}_{\mathrm{e}}$, em cada cuba, foi calculada pela Equação 13 através de um balanço de massa.

$$
q_{e}=\frac{V\left(C_{0}-C_{e}\right)}{W}
$$

em que: $V=$ volume da solução inicial (L); $C_{0}=$ concentração inicial de DQO da solução $(\mathrm{mg} / \mathrm{L}) ; C_{e}=$ concentração de DQO da solução obtida no equilíbrio $(\mathrm{mg} / \mathrm{L}) ; W=$ massa de lodo puro adicionada $(\mathrm{mg})$.

\section{Avaliação da sedimentabilidade do lodo gerado do POA/Fenton}

O ensaio foi realizado através do teste de proveta. $^{7}$ Adicionou-se a uma proveta de vidro com volume de $1 \mathrm{~L}$ uma quantidade com o mesmo volume de amostra (efluente pós-POA), deixada em repouso 
até que a variação da altura da interface sólido/líquido fosse encerrada ou atingisse um tempo máximo de $2 \mathrm{~h}$, caracterizando o fim do processo de sedimentação. A cada 3 min a altura da interface sólido/ líquido foi registrada para o levantamento da curva de sedimentação. O valor da altura da interface utilizado para o cálculo do IVL (Índice Volumétrico de Lodo) foi o correspondente ao tempo de 30 min. Determinou-se a concentração de sólidos suspensos totais da amostra para cálculo do IVL. Os valores de IVL foram determinados de acordo com a Equação 14.

$$
\mathrm{IVL}=\frac{H_{30} \times 10^{6}}{H_{0} \times S S T}
$$

onde: $I V L=$ índice volumétrico de lodo $\left(\mathrm{mL} \mathrm{g}^{-1}\right) ; H_{30}=$ altura da interface após $30 \mathrm{~min}$ do início do teste $(\mathrm{m}) ; H_{0}=$ altura da interface no início do teste $(\mathrm{m}) ; S S T=$ concentração de sólidos suspensos totais $\left(\mathrm{mg} \mathrm{L}^{-1}\right)$.

Por fim, determinou-se a velocidade de sedimentação como sendo a média das velocidades atingida antes do tempo crítico de sedimentação. Os ensaios foram realizados com o efluente pós-POA neutralizado em pH 7,0 a favor da melhor condição de sedimentação.

\section{RESULTADOS}

\section{Avaliação do POA/Fenton}

Parâmetros convencionais

A Tabela 3 apresenta os valores dos parâmetros avaliados na caracterização físico-química convencional do lixiviado bruto e efluente pós-POA/Fenton. Ressalta-se que a caracterização do efluente tratado se refere à fração sobrenadante sem o emprego da etapa de neutralização. Para esta caracterização foram realizados dez ensaios de POA, em condições otimizadas, para diferentes coletas de lixiviado bruto.

Em relação à remoção de cor e poluentes orgânicos, pode-se observar uma significativa remoção após o tratamento. Observouse uma eficiência de remoção de cor e DQO de 76,4 e 76,7\%, respectivamente. Estes valores concordam com os valores obtidos por Lange et al.,$^{15}$ que usaram POA para tratamento de lixiviado. A DQO persistente pode ser justificada pela formação de produtos intermediários estáveis, que requerem um maior tempo para oxidação. Vale ressaltar que os valores de DQO foram corrigidos em função da interferência do peróxido residual e da concentração de ferro nos ensaios de DQO. Notou-se um aumento significativo da relação DBO/ DQO, reforçando o citado na literatura de que o POA/Fenton atribui

Tabela 3. Caracterização físico-química convencional do lixiviado bruto e sobrenadante do efluente pós-POA/Fenton

\begin{tabular}{|c|c|c|c|c|c|c|c|c|c|}
\hline \multirow{2}{*}{$\begin{array}{l}\text { Parâmetros } \\
\text { físico-químicos }\end{array}$} & \multirow{2}{*}{ Unidade } & \multicolumn{4}{|c|}{ Lixiviado bruto } & \multicolumn{4}{|c|}{ Pós-POA (*SN) } \\
\hline & & Máx. & Mín. & Média & Desvio & Máx. & Mín. & Média & Desvio \\
\hline Cor real & $\mathrm{uH}$ & 568 & 420 & 467 & 60 & 128 & 92 & 110 & 12 \\
\hline Cor aparente & $\mathrm{uH}$ & 748 & 519 & 590 & 94 & 149 & 107 & 129 & 14 \\
\hline DQO & $\mathrm{mg} \mathrm{L}^{-1}$ & 2.428 & 2.220 & 2.354 & 94 & 588 & 471 & 548 & 41 \\
\hline $\mathrm{DBO}_{5}$ & $\mathrm{mg} \mathrm{L}^{-1}$ & 85 & 50 & 68 & 15 & 150 & 80 & 111 & 24 \\
\hline DBO/DQO & - & 0,04 & 0,02 & 0,03 & 0,01 & 0,26 & 0,14 & 0,20 & 0,04 \\
\hline Carbono Total & $\mathrm{mg} \mathrm{L}^{-1}$ & 2.392 & 2.217 & 2.304 & 71 & 384 & 344 & 367 & 17 \\
\hline Carbono Inorgânico & $\mathrm{mg} \mathrm{L}^{-1}$ & 1.384 & 1.142 & 1.254 & 97 & 56 & 17 & 37 & 18 \\
\hline COT & $\mathrm{mg} \mathrm{L}^{-1}$ & 1.090 & 1.008 & 1.052 & 34 & 352 & 315 & 331 & 16 \\
\hline $\mathrm{pH}$ & - & 8,4 & 8,1 & 8,3 & 0,2 & 3,1 & 2,8 & 2,9 & 0,1 \\
\hline Nitrogênio Total & $\mathrm{mg} \mathrm{L}^{-1}$ & 1.172 & 1.036 & 1.105 & 57 & 1.137 & 1.032 & 1.085 & 45 \\
\hline Nitrogênio Amoniacal & $\mathrm{mg} \mathrm{L}^{-1}$ & 1.144 & 941 & 1.055 & 85 & 1.113 & 931 & 1.042 & 70 \\
\hline Cloretos & $\mathrm{mg} \mathrm{L}^{-1}$ & 2.333 & 2.033 & 2.190 & 124 & 2.266 & 1.966 & 2.127 & 114 \\
\hline Alcalinidade & $\mathrm{mg} \mathrm{L}^{-1}$ & 6.041 & 4.791 & 5.263 & 557 & - & - & - & - \\
\hline Fósforo & $\mathrm{mg} \mathrm{L}^{-1}$ & 19,6 & 11,3 & 14,5 & 3,7 & 11,2 & 2,7 & 6,4 & 3,1 \\
\hline ST & $\mathrm{mg} \mathrm{L}^{-1}$ & 9.408 & 8.120 & 8.801 & 591 & 11.318 & 8.554 & 9.743 & 1.002 \\
\hline STF & $\mathrm{mg} \mathrm{L}^{-1}$ & 6.002 & 5.114 & 5.595 & 370 & 4.384 & 3.144 & 3.715 & 445 \\
\hline STV & $\mathrm{mg} \mathrm{L}^{-1}$ & 3.736 & 2.452 & 3.227 & 614 & 7.207 & 5.332 & 6.044 & 688 \\
\hline SST & $\mathrm{mg} \mathrm{L}^{-1}$ & 26,5 & 17,0 & 22,4 & 4,1 & 4,7 & 3,0 & 3,9 & 0,7 \\
\hline SSF & $\mathrm{mg} \mathrm{L}^{-1}$ & 4,5 & 1,5 & 3,1 & 1,4 & 2,0 & 0,3 & 0,9 & 0,6 \\
\hline SSV & $\mathrm{mg} \mathrm{L}^{-1}$ & 22,0 & 15,5 & 19,3 & 2,8 & 4,0 & 2,0 & 3,0 & 0,8 \\
\hline Cádmio & $\mathrm{mg} \mathrm{L}^{-1}$ & 0,524 & $<0,005$ & 0,466 & 0,264 & 0,289 & $<0,005$ & 0,158 & 0,135 \\
\hline Chumbo & $\mathrm{mg} \mathrm{L}^{-1}$ & $<0,02$ & $<0,02$ & $<0,02$ & - & $<0,02$ & $<0,02$ & $<0,02$ & 0 \\
\hline Cromo & $\mathrm{mg} \mathrm{L}^{-1}$ & 0,49 & $<0,05$ & 0,23 & 0,23 & 0,32 & $<0,05$ & 0,16 & 0,13 \\
\hline Ferro & $\mathrm{mg} \mathrm{L}^{-1}$ & 10,35 & 2,20 & 5,68 & 3,60 & 318,90 & 178,38 & 269,91 & 53,02 \\
\hline Zinco & $\mathrm{mg} \mathrm{L}^{-1}$ & 0,14 & 0,07 & 0,10 & 0,03 & 0,33 & 0,02 & 0,14 & 0,11 \\
\hline
\end{tabular}

*SN - sobrenadante. ST - Sólidos Totais, STF - Sólidos Totais Fixos, STV - Sólidos Totais Voláteis, SST - Sólidos Suspensos Totais, SSF - Sólidos Suspensos Fixos, SSV - Sólidos Suspensos Voláteis 
biodegradabilidade ao efluente. Este fato se sustenta na oxidação química aleatória de compostos não biodegradáveis, resultando na formação de produtos intermediários biodegradáveis justificando o incremento de DBO observado.

Ainda com referência aos compostos orgânicos, a remoção do COT foi de $67 \%$. A relação DQO/COT foi testada no lixiviado tratado com várias concentrações de DQO, encontrando-se resultado médio igual a 2,9, valor próximo ao encontrado para o lixiviado bruto, demonstrando uma uniformidade desta relação.

Os baixos valores de $\mathrm{pH}$ são consequência da acidificação exigida pelo POA/Fenton, onde o valor ótimo empregado para o lixiviado em estudo, conforme determinado anteriormente, foi de 3,8 . Notouse uma redução do pH após a reação de oxidação. Este fato pode estar relacionado com a formação de íons $\mathrm{H}^{+}$durante a reação de oxidação e, também, de ácidos carbônicos resultantes do $\mathrm{CO}_{2}$ gerado na mineralização da matéria orgânica. $\mathrm{O}$ decréscimo dos valores de alcalinidade após o tratamento, que pode estar associado à reação de $\mathrm{PO}_{4}^{-3}$ e $\mathrm{CO}_{3}^{-2}$ com o radical hidroxila $\left({ }^{\circ} \mathrm{OH}\right)$, provavelmente está relacionado com o decréscimo do $\mathrm{pH}$.

O POA/Fenton não atuou satisfatoriamente na remoção de nitrogênio e fósforo, cujas concentrações permaneceram elevadas após o tratamento. A concentração de sólidos totais no lixiviado após o processo oxidativo aumentou, indicando geração de lodo após a etapa de tratamento. Com base nestes resultados, diferentemente do esperado, pode-se inferir que mesmo após o tratamento ainda persistem substâncias de natureza orgânica, no efluente sobrenadante, afirmação essa reforçada pela relação STV/ST $(0,62)$ maior do que a do lixiviado bruto $(0,36)$.

Os metais apresentaram-se em concentrações constantes antes e pós-tratamento. A remoção do cádmio pode estar relacionada com o fenômeno de adsorção uma vez que, com exceção do ferro, se apresenta em concentrações bem mais altas do que os outros metais avaliados. As altas concentrações de ferro após o POA/Fenton são explicadas pelo emprego de sulfato ferroso hepta-hidratado como catalisador do processo.

O conhecimento dos constituintes do lodo gerado no POA/Fenton permite o entendimento de suas propriedades podendo, assim, contribuir para uma melhor compreensão da reação de oxidação e possíveis soluções deste passivo do tratamento. Após decantação (sem o auxílio da neutralização) e posterior descarte da fração sobrenadante, o lodo foi separado, homogeneizado e caracterizado, sendo os resultados apresentados na Tabela 4.

Tabela 4. Caracterização físico-química do lodo gerado no POA/Fenton

\begin{tabular}{lccccc}
\hline $\begin{array}{l}\text { Parâmetros } \\
\text { físico-químicos }\end{array}$ & Unidade & \multicolumn{4}{c}{ Lodo gerado no POA } \\
& & Máx. & Mín. & Média & Desvio \\
\hline DQO & $\mathrm{mg} \mathrm{L}^{-1}$ & 2.857 & 2.037 & 2.465 & 285 \\
CT & $\mathrm{mg} \mathrm{L}^{-1}$ & 2.070 & 1.335 & 1.734 & 304 \\
pH & - & 2,9 & 2,8 & 2,9 & 0,1 \\
ST & $\mathrm{g} \mathrm{L}^{-1}$ & 13,5 & 12,3 & 12,9 & 0,4 \\
STF & $\mathrm{g} \mathrm{L}^{-1}$ & 6,8 & 5,7 & 6,4 & 0,4 \\
STV & $\mathrm{g} \mathrm{L}^{-1}$ & 7,0 & 6,2 & 6,5 & 0,3 \\
Ferro & $\mathrm{mg} \mathrm{L}^{-1}$ & $2.116,5$ & $1.272,3$ & $1.756,5$ & 298,7 \\
\hline
\end{tabular}

ST- Sólidos Totais, STF - Sólidos Totais Fixos, STV - Sólidos Totais Voláteis

A concentração de compostos de natureza orgânica no lodo pode ser confirmada pelos altos valores de DQO encontrados. Este fato reforça ainda mais o acontecimento do fenômeno de adsorção durante o POA/ Fenton. Vale ressaltar ainda que esses valores foram corrigidos em fun- ção da interferência da concentração de ferro nos ensaios de DQO. A concentração de CT no lodo foi elevada, situando-se próximo de 1.734 $\mathrm{mg} \mathrm{L}^{-1}$, corroborando o afirmado anteriormente. Os valores de $\mathrm{pH}$ do lodo apresentaram-se compatíveis com os encontrados no sobrenadante, indicando assim estabilidade da reação de oxidação. Em relação à natureza dos sólidos presentes no lodo, observou-se uma relação STV/ ST igual a 0,50 , confirmando a presença de compostos orgânicos no lodo, fato esse confirmado pelas concentrações equilibradas de STF e STV. A fração de STF pode ser atribuída à precipitação do ferro na forma de hidróxidos, além de outros compostos mineralizados. A alta concentração de ferro no lodo reforça esta afirmativa.

\section{DQO inerte versus biodegradabilidade}

Observou-se uma fração de DQO inerte do lixiviado bruto e tratado igual a 44 e $40 \%$, respectivamente. Nestes resultados não se observou alteração significativa de fração de DQO inerte após o tratamento, sugerindo assim que os compostos intermediários gerados no POA apresentam natureza refratária em vista de que a eficiência de remoção de DQO é elevada.

O lixiviado bruto apresentou biodegradabilidade máxima de 46,6\%, sendo que após o tratamento o efluente pós-POA apresentou um sensível aumento de biodegradabilidade em condições aeróbias $(65,8 \%)$ como consequência da oxidação parcial de poluentes complexos.

De modo geral, apesar da elevada eficiência atingida no POA/ Fenton, este processo ainda não é capaz de enquadrar o efluente de acordo com os padrões estabelecidos pela legislação vigente, sugerindo assim a necessidade de um tratamento complementar para este fim.

\section{Distribuição de massa molar}

Na Figura 1 são apresentadas as caracterizações das frações das amostras de lixiviado bruto e pós-POA obtidas da ultrafiltração com membranas de 1, 5, 10 e $100 \mathrm{kDa}$. Os resultados obtidos são referentes à média dos ensaios realizados em triplicata para cada efluente. As figuras apresentam, para cada fração de massa molar, o percentual e a concentração de carboidratos, lipídeos, proteínas e substâncias húmicas expressos em DQO. A denominação "outros” foi atribuída à fração de compostos não identificada, quantificados pela diferença entre os valores de DQO e o somatório da fração de carboidratos, lipídeos, proteínas e substâncias húmicas expressos em DQO.

Em relação aos compostos com massa molar menor que $1 \mathrm{kDa}$, proteínas, carboidratos e lipídeos foram oxidados quase totalmente pelo agente oxidante, enquanto que a fração de substâncias húmicas, apesar da significativa remoção $(60 \%)$, persistiu. A fração denominada "outros" apresentou incremento de seu valor. Este aumento pode ser associado aos produtos intermediários produzidos durante o processo oxidativo. A não subsequente oxidação destes compostos pode ser relacionada à cinética de degradação desfavorável destes compostos, uma vez que os ensaios foram realizados em condições otimizadas não havendo, assim, limitações de concentração de reagentes. Este fato corrobora a hipótese de que as substâncias húmicas e fração denominada "outros" apresentam natureza refratária, uma vez que o efluente final é constituído principalmente destas frações.

A atribuição de biodegradabilidade do POA também pode estar associada, principalmente, à mineralização total ou parcial de substâncias húmicas presentes com massa molar entre 10 e 100 kDa, referenciada como ácidos húmicos, por sua característica inerte e concentração expressiva nestas faixas.

\section{Substâncias húmicas}

A Figura 2 apresenta os resultados quantitativos encontrados das substâncias húmicas presentes no lixiviado bruto e efluente pós-POA/ Fenton, bem como no lodo gerado do POA/Fenton. 


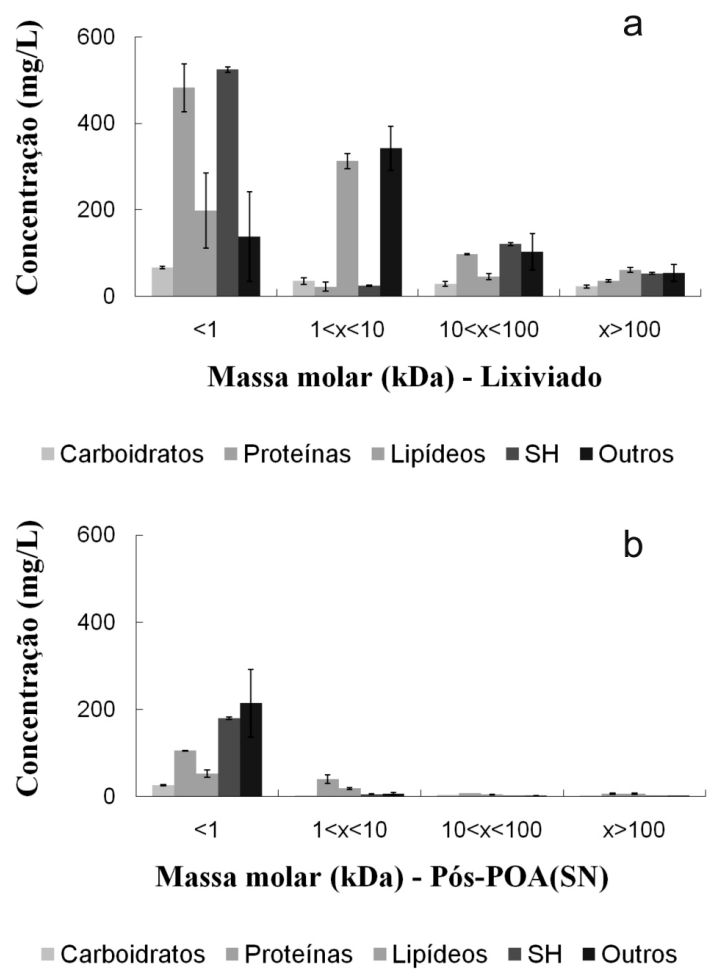

Figura 1. Distribuição de massa molar: (a) lixiviado bruto; (b) efluente pós-POA/Fenton

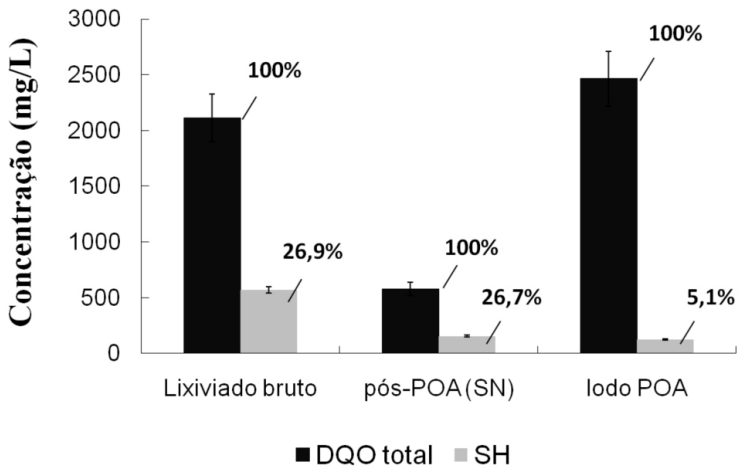

Figura 2. Concentração de substâncias húmicas e DQO total do lixiviado bruto, efluente pós-POA/Fenton e do lodo gerado no POA/Fenton

Os ensaios mostraram uma eficiência de oxidação de substâncias húmicas de 50,3\%, sendo que do percentual remanescente, $27,2 \%$ se encontram dissolvidas no sobrenadante e $22,4 \%$ adsorvidas no lodo gerado. Nota-se também que essas substâncias representam o mesmo percentual (aproximadamente $27 \%$ ) em relação à DQO total, tanto para o lixiviado bruto quanto para o tratado. No lodo, essas substâncias representam apenas $5,1 \%$ do total de DQO, o que representa baixa adsortividade das substâncias húmicas.

Dentre as espécies de substâncias húmicas, foi caracterizado quase que a totalidade de ácidos fúlvicos no lixiviado tratado $(99,2 \%)$, enquanto os ácidos húmicos representaram 0,6\%. Este resultado pode ser compreendido através da eficácia do POA em frações de maiores massas molares. Nas espécies de substâncias húmicas do lodo gerado no POA, detectou-se um percentual de ácidos fúlvicos e ácidos húmicos de 80,0 e 16,3\%, respectivamente. O percentual de ácidos húmicos no lodo do POA foi compatível com o encontrado no lixiviado bruto, resultado da adsorção destas substâncias quando ainda no início da reação de oxidação.

\section{Avaliação da capacidade adsortiva do lodo gerado no POA/ Fenton}

\section{Cinética de adsorção}

Os experimentos cinéticos foram realizados pelo modo estático, com massa conhecida de lodo, em contato com lixiviado com diferentes concentrações de matéria orgânica em termos de DQO obtidas através de diluições do lixiviado bruto, em pH 8,3 (bruto), sendo que os experimentos se estenderam por $24 \mathrm{~h}$ à $25 \pm 2{ }^{\circ} \mathrm{C}$, com retiradas de alíquotas periódicas e analisadas quanto à DQO. Os resultados mostraram uma maior adequação do modelo cinético de pseudossegunda ordem. A Tabela 5 apresenta os coeficientes obtidos de cada modelo cinético testado e seus respectivos coeficientes de correlação.

O modelo de pseudossegunda ordem apresentou melhor correlação aos dados $(\mathrm{R}>0,99)$. Este modelo assume que a quimiossorção é o mecanismo dominante e controla a adsorção. ${ }^{16}$ Na Figura 3 são apresentadas as curvas resultantes da aplicação do modelo de pseudossegunda ordem aos dados de adsorção em termos de DQO para o lixiviado, com diferentes concentrações de matéria orgânica.

Os valores do parâmetro $\mathrm{ka}_{2}$ diminuem com o aumento da concentração de matéria orgânica no lixiviado, o que já era esperado uma vez que com o aumento da concentração de matéria orgânica no meio se reduz também o número de sítios ativos disponíveis para adsorção em função da saturação do adsorvente.

\section{Isotermas de adsorção}

Para melhor compreensão do fenômeno de adsorção das substâncias orgânicas por parte do lodo gerado no POA, foram realizados estudos de equilíbrio e posterior construção da isoterma de adsorção. Primeiramente foi avaliado o efeito do tempo de adsorção no equilíbrio da adsorção para os ensaios realizados com lixiviado com diferentes concentrações de matéria orgânica em termos de DQO. Na Tabela 6 são apresentados os coeficientes experimentais obtidos para os modelos de isotermas de equilíbrio aplicados na avaliação

Tabela 5. Coeficientes experimentais dos modelos cinéticos avaliados na cinética de adsorção

\begin{tabular}{|c|c|c|c|c|c|c|c|}
\hline \multirow[b]{2}{*}{$\begin{array}{l}\text { DQO inicial } \\
\left(\mathrm{mg} \mathrm{L}^{-1}\right)\end{array}$} & \multirow[b]{2}{*}{$\begin{array}{c}\mathrm{q}_{\mathrm{e}}, \exp \\
\left(\mathrm{mg} \mathrm{g}^{-1}\right)\end{array}$} & \multicolumn{3}{|c|}{ Pseudoprimeira ordem } & \multicolumn{3}{|c|}{ Pseudossegunda ordem } \\
\hline & & $\begin{array}{c}\mathrm{q}_{\mathrm{e}}, \mathrm{cal} \\
\left(\mathrm{mg} \mathrm{g}^{-1}\right)\end{array}$ & $\begin{array}{l}\mathrm{ka}_{1} \\
\left(\mathrm{~h}^{-1}\right)\end{array}$ & $\mathrm{R}^{2}$ & $\begin{array}{c}\mathrm{q}_{\mathrm{e}}, \mathrm{cal} \\
\left(\mathrm{mg} \mathrm{g}^{-1}\right)\end{array}$ & $\begin{array}{c}\mathrm{ka}_{2} \\
\left(\mathrm{~g} \mathrm{mg}^{-1} \min \right)\end{array}$ & $\mathrm{R}^{2}$ \\
\hline 2211 & 960,49 & 170,37 & 0,3161 & 0,7015 & $1.000,00$ & 0,0025 & 0,9994 \\
\hline 1689 & 801,29 & 119,27 & 0,2650 & 0,6456 & 833,33 & 0,0036 & 0,9994 \\
\hline 1266 & 479,76 & 89,97 & 0,2642 & 0,7223 & 500,00 & 0,0067 & 0,9998 \\
\hline 844 & 366,37 & 57,88 & 0,2472 & 0,6896 & 370,37 & 0,0104 & 0,9999 \\
\hline 422 & 211,69 & 29,90 & 0,1938 & 0,6186 & 217,39 & 0,0192 & 0,9998 \\
\hline
\end{tabular}


$\cdot 422 \mathrm{mg} / \mathrm{L} \cdot 844 \mathrm{mg} / \mathrm{L} \cdot 1266 \mathrm{mg} / \mathrm{L} \cdot 1689 \mathrm{mg} / \mathrm{L} \cdot 2211 \mathrm{mg} / \mathrm{L}$

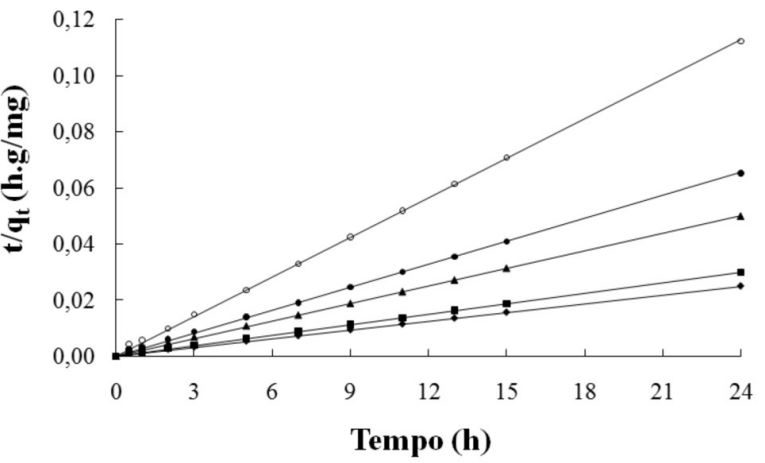

Figura 3. Resumo dos modelos cinéticos de pseudossegunda ordem

Tabela 6. Coeficientes experimentais para diferentes modelos de isotermas de equilíbrio aplicadas na avaliação da adsorção

\begin{tabular}{lccc}
\hline Isoterma & Coeficientes & Unidade & Valor \\
\hline \multirow{2}{*}{ Langmuir } & $\mathrm{q}_{\mathrm{m}}$ & $\mathrm{mg} \mathrm{g}^{-1}$ & $2.000,00$ \\
& $\mathrm{~K}$ & $\mathrm{~L} \mathrm{mg}^{-1}$ & 0,00049 \\
Freundlich & $\mathrm{K}$ & $\mathrm{L} \mathrm{mg}^{-1}$ & 1,98 \\
& $\mathrm{n}$ & - & 1,18 \\
BET & $\mathrm{K}$ & $\mathrm{L} \mathrm{mg}^{-1}$ & 8,67 \\
& $\mathrm{~B}$ & - & 384,61 \\
\hline
\end{tabular}
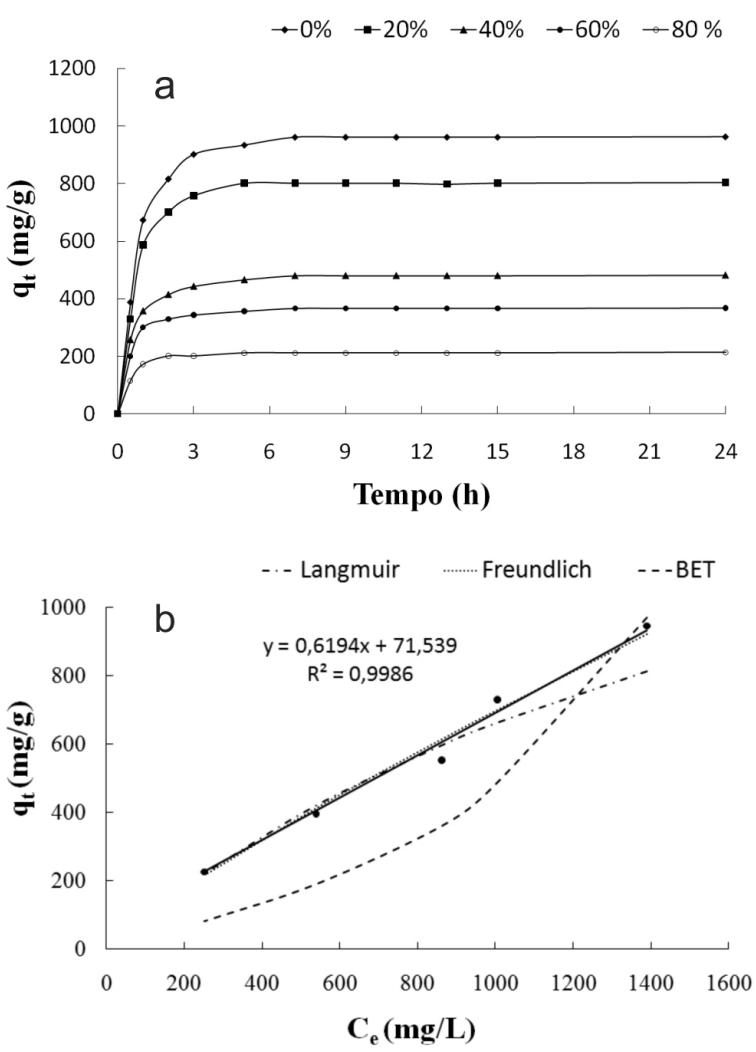

Figura 4. (a) Efeito do tempo de agitação no equilíbrio de adsorção para as diferentes concentrações de $D Q O$ avaliadas em relação à remoção de $D Q O$; (b) isotermas de adsorção experimental e referenciada na literatura da adsorção. Na Figura 4a, é apresentado o efeito do tempo para o equilíbrio da adsorção, enquanto que na Figura 4b é apresentada a isoterma de adsorção obtida para os dados experimentais e sua respectiva comparação com as isotermas sugeridas: Langmuir, Freundlich e BET.

Observa-se, pela Figura 4a, que ocorre uma rápida adsorção inicial seguida pela redução da taxa de adsorção. A etapa de rápida adsorção provavelmente está relacionada com a difusão na camada limite. Após os instantes iniciais da adsorção, a velocidade diminui, devido à difusão do soluto na estrutura interna do adsorvente. Observa-se que quanto maior a quantidade de matéria orgânica disponível no meio, mais suavemente as substâncias são adsorvidas no lodo. Entretanto, para menores quantidades de matéria orgânica disponível no meio a adsorção inicial é rápida, indicando uma rápida interação entre as substâncias a serem adsorvidas e o lodo.

Observa-se também que a quantidade de substância adsorvida pelo lodo aumenta com o tempo até atingir um valor a partir do qual não é possível a remoção de mais substâncias do meio. Neste ponto a quantidade adsorvida pelo lodo atingiu o equilíbrio dinâmico. $\mathrm{Na}$ Figura 4b é apresentada a correlação entre a concentração de DQO da fase líquida com a quantidade de matéria orgânica adsorvida pelo lodo no equilíbrio para os dados obtidos experimentalmente e sua respectiva comparação com as isotermas de Langmuir, Freundlich e BET. Pode-se verificar, assim, que os dados experimentais seguem comportamento de acordo com a isoterma de Freundlich.

\section{Avaliação da sedimentabilidade do lodo gerado do POA/Fenton}

O perfil de sedimentação do lodo gerado no POA/Fenton foi avaliado através da curva de sedimentação obtida no teste da proveta. Na Figura 5 é apresentada a curva resposta do teste.

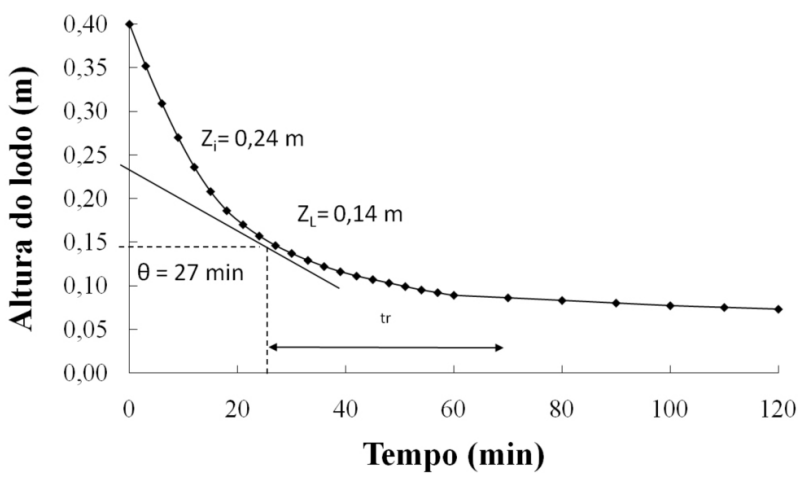

Figura 5. Curva de sedimentação do lodo gerado no POA

Nota-se que o tempo crítico de sedimentação, ou seja, aquele a partir do qual se podem observar apenas duas fases no líquido, foi de 27 min. Foi observado também o término do tempo de compactação do lodo próximo aos 70 min de ensaio. A velocidade média de sedimentação calculada foi de $0,56 \mathrm{~m} \mathrm{~h}^{-1}$. Estes resultados indicam baixa sedimentabilidade do lodo gerado no POA. De acordo com von Sperling, ${ }^{17}$ o lodo pós-POA apresentou classificação referente ao IVL como de péssima sedimentabilidade (> $\left.300 \mathrm{~mL} \mathrm{~g}^{-1}\right)$. Na Tabela 7 é apresentado o resultado obtido.

Tabela 7. IVL do lodo gerado pós-POA

\begin{tabular}{lcccc}
\hline Amostra & $\mathrm{SST}\left(\mathrm{mg} \mathrm{L}^{-1}\right)$ & $\mathrm{Z}_{0^{\prime}}(\mathrm{m})$ & $\mathrm{Z}_{30^{\circ}}(\mathrm{m})$ & $\mathrm{IVL}\left(\mathrm{mL} \mathrm{g}^{-1}\right)$ \\
\hline Pós-POA + lodo & 1.067 & 0,137 & 0,400 & 321 \\
\hline
\end{tabular}




\section{CONCLUSÕES}

Em relação ao POA/Fenton, verificou-se uma eficiência de remoção de cor e DQO de 76,4 e 76,7\%, respectivamente. Esta técnica não atuou satisfatoriamente na remoção de outros poluentes, tais como, nutrientes (nitrogênio e fósforo), cloretos, alcalinidade e metais, cujas concentrações praticamente persistiram ou ainda permaneceram elevadas após o tratamento. Observou-se também uma fração de DQO inerte do lixiviado bruto e tratado próxima a $40 \%$, sugerindo que os compostos intermediários gerados no POA apresentam natureza refratária. Em relação à distribuição molar de compostos orgânicos, o POA/Fenton foi eficiente na remoção de todas as frações de massa molar, onde praticamente os compostos persistentes possuem massas molares inferiores a $5 \mathrm{kDa}$. Os ensaios mostraram ainda uma eficiência de oxidação de substâncias húmicas de 50,3\%, sendo que do percentual remanescente, $27,2 \%$ se encontram dissolvidas no sobrenadante e $22,4 \%$ adsorvidas no lodo gerado. Dentre as espécies de substâncias húmicas, foi caracterizado quase que a totalidade de ácidos fúlvicos no lixiviado tratado $(99,2 \%)$.

O estudo cinético de adsorção da reação Fenton mostrou ajuste adequado de acordo com o modelo cinético de pseudossegunda ordem e, também, indicou significativa adsorção de matéria orgânica no lodo formado durante a reação.

O POA baseado no reagente de Fenton se mostrou adequado para o tratamento de lixiviado com características refratárias. No entanto, a eficiência deste processo quando aplicado de forma isolada não permitiu o enquadramento deste efluente tratado nos padrões de lançamento de efluentes vigente no Estado de Minas Gerais (Deliberação Normativa Conjunta COPAM/CERH-MG n 1, de 5/5/2008), sugerindo a necessidade de um pós-tratamento.

\section{AGRADECIMENTOS}

Ao $\mathrm{CNPq}$ (Conselho Nacional de Desenvolvimento Científico e Tecnológico) e à FAPEMIG (Fundação de Amparo à Pesquisa do Estado de Minas Gerais).

\section{REFERÊNCIAS}

1. Gomes, L. P. Em Estudos de caracterização e tratabilidade de lixiviados de aterros sanitários para as condições brasileiras; Gomes L. P.; Cantanhede, A. L. G.; Amorim, A. K. B.; Castilhos Jr., A. B.; Fernandes, F.; Ferreira, J. A.; Jucá, J. F. T.; Lange, L. C.; Leite, V. D., eds.; ABES: Rio de Janeiro, 2009.

2. Kurniawan, T. A.; Lo, W.; Chan, G. Y. S.; J. Hazard. Mater. 2006, 129, 80.

3. Englehardt, J. D.; Deng, Y.; Meeroff, D.; Legrenzi, Y.; Mognol, J.; Polar, J.; Technical Report; University of Florida, EUA, 2006.

4. Li, W.; Zhou, Q.; Hua, T.; International Journal of Chemical Engineering (2010), doi:10.1155/2010/270532.

5. Deng, Y.; Englehardt, J. D.; Water Res. 2006, 40, 3683.

6. Barros Neto, B.; Scarminio, I. S; Bruns, R. E.; Como fazer experimentos: pesquisa e desenvolvimento na ciência e na indústria, Ed. da Unicamp: Campinas, 2003.

7. Neyens, E.; Baeyens, J.; J. Hazard. Mater. 2003, 98, 33.

8. Standard Methods for the Examination of Water and Wastewater, $21^{\text {th }}$ ed. (CD), 2005.

9. Germili, E.; Orhon, D.; Artan, N.; Water Sci. Technol. 1991, 23, 1077.

10. Detailed review paper on biodegradability testing, OECD Environment Monograph, 1995.

11. Frolund, B.; Griebe, T.; Nielsen, P. H.; Appl. Microbiol. Biotechnol. 1995, 43, 755

12. Lowry, O. H.; Rosenbrough, N. J.; Farr, R. L.; Randall, R. J.; J. Biol. Chem. 1951, 193, 265.

13. McBride, M. B.; Environmental chemistry of soils, Oxford University Press: New York, 1994.

14. Moravia, W. G.; Tese de Doutorado, Universidade Federal de Minas Gerais, Brasil, 2010.

15. Lange, L. C.; Alves, J. F.; Amaral, M. C. S.; Melo Jr., W. R.; Eng. Sanit. e Amb. 2006, 11, 175.

16. Ho, Y. S.; Mckay, G.; Chem. Eng. J. 1998, 70, 115.

17. von Sperling, M.; Eng. Sanit. e Amb. 2001, 6, 149. 